\title{
Diagnóstico e recuperação de áreas de pastagens degradadas
}

Daniel Nogueira Pereira ${ }^{1}$

Thiago Cardoso de Oliveira ${ }^{2}$

Thales Eugênio de Brito ${ }^{3}$

Jorge Augusto Figueiredo Agostini ${ }^{4}$

Paulo Felipe Lima 5

Ariana Vieira Silva ${ }^{6}$

Claudiomir Silva Santos ${ }^{7}$

Marcelo Bregagnoli ${ }^{8}$

\section{1 | Introdução}

As pastagens brasileiras, em sua maioria, vêm sendo exploradas ao longo dos anos dentro de um sistema extrativista, utilizando-se da fertilidade natural dos solos para implantação de forrageiras e, à medida que esta fertilidade vai diminuindo, o potencial produtivo da forrageira instalada é dirimido, provocando uma queda na capacidade de suporte de animais nessas áreas. Devido a esta diminuição da fertilidade do solo e do potencial das forrageiras, muitas vezes abandonam-se as áreas utilizadas e abrem-se novas áreas para a implantação de novos pastos. Cordeiro et al. (2004) aponta que este uso inadequado e intensivo de áreas exploradas pelas atividades antrópicas tem proporcionado um declínio demasiado da fertilidade natural dos solos.

As pastagens devem ser manejadas como ecossistemas naturalmente, tal como são, possibilitando a produção de forragem e carne.
Porém, o manejo deve estar em equilíbrio com o meio, mantendo assim a fertilidade do solo, sua microbiologia, suas características físicas e a harmonia com as demais espécies silvestres e com a paisagem local.

Os princípios da ecologia são aplicados no manejo das pastagens nativas, consistindo na manipulação do ambiente de sobrevivência de plantas e animais, de modo a Ihes propiciar um habitat mais favorável. O animal em pastejo é parte integrante do ambiente da planta e vice versa, onde o bem estar de um influencia o bem estar do outro e ambos influenciam o ambiente produtivo (BARBOSA, 2001).

O manejo incorreto dos solos provoca degradação e alterações nos ecossistemas, como consequência da desvinculação entre o crescimento econômico e o desenvolvimento sustentável (ALVARENAGA; DAVIDE, 1999).

\footnotetext{
Discente de Engenharia Agronômica do IFSULDEMINAS, campus Muzambinho, daniel_nogueirapereira@hotmail.com Discente de Engenharia Agronômica do IFSULDEMINAS, campus Muzambinho, thiagocardoso@agronomo.eng.br Discente de Engenharia Agronômica do IFSULDEMINAS, campus Muzambinho, thalestp@hotmail.com Discente de Engenharia Agronômica do IFSULDEMINAS, campus Muzambinho, jorge_augustoagostini@hotmail.com Discente de Engenharia Agronômica do IFSULDEMINAS, campus Muzambinho, paulofelipecrc@hotmail.com

Docente do IFSULDEMINAS, campus Muzambinho, ariana.silva@muz.ifsuldeminas.edu.br

Docente do IFSULDEMINAS, campus Muzambinho, claudiomir@eafmuz.gov.br

Docente do IFSULDEMINAS, campus Muzambinho, marcelo.bregagnolli@ifsuldeminas.edu.br
} 
Os sistemas naturais modificados pela ação humana dão origem a áreas alteradas com sua capacidade melhorada, conservada ou diminuída. Quando essa alteração se associa a processos que ocasionam a perda da capacidade produtiva do agrossistema, diz-se que as áreas estão degradadas, e áreas degradadas estão altamente susceptíveis a processo erosivos (SILVA, 2011).

Dentre os maiores processos degradantes do solo, destaca-se a erosão dos solos, que repercute na dinâmica das águas e onera a sociedade, pois, além de danos ambientais irreversíveis, produz também prejuízos econômicos e sociais (OLIVEIRA JÚNIOR et al., 1990).

O objetivo deste trabalho foi diagnosticar áreas de manejo inadequado do solo e de pastagens e propor soluções aplicáveis para o controle destes problemas.

\section{2 | Material e métodos}

O trabalho foi realizado na Fazenda Mandasaia, município de Alterosa, MG, Coordenada Geográfica UTM: 23 k 393574,764 E. x $7647413,000 \mathrm{~N}$. A propriedade localizada ocupa uma área de 60 ha, toda explorada como área de pastagem (Brachiaria decumbens L.).
Quanto ao clima e relevo, a temperatura varia de mínima $0^{\circ} \mathrm{C}$ a $30^{\circ} \mathrm{C}$ de máxima anual, 840 $\mathrm{m}$ de altitude; com índice médio pluviométrico anual de $1.638 \mathrm{~mm}$. (GOMES, 2006), e o solo da propriedade é um Latossolo Vermelho Distrófico. A propriedade está localizada na baciahidrográfica do Rio Grande e na sub-bacia do entorno do lago de Furnas.

Em levantamento in loco foi observada uma área de pastagem em avançado estágio erosivo, tomando a propriedade em sua totalidade (Figura 1).

Segundo Stoddart, Smith e Box (1975), alguns estágios da degradação são característicos para a maioria das pastagens e podem ser facilmente identificados: (1) Distúrbios fisiológicos da espécie dominante; (2) Mudanças na composição botânica e (3) Invasão por novas espécies.

Para determinação do estado de degradação da pastagem e para tomada de decisão quanto ao procedimento de recuperação ou reforma de pastagens degradadas, utilizou-se de metodologia descrita por Oliveira e Corsi (2005) (Figura 2), onde se estuda a área de solo exposta e a partir desta informação define-se a melhor opção para o diagnóstico encontrado.
Figura 1: Área de pastagem degrada na zona rural do município de Alterosa/MG. Fonte: NOGUEIRA (2012).

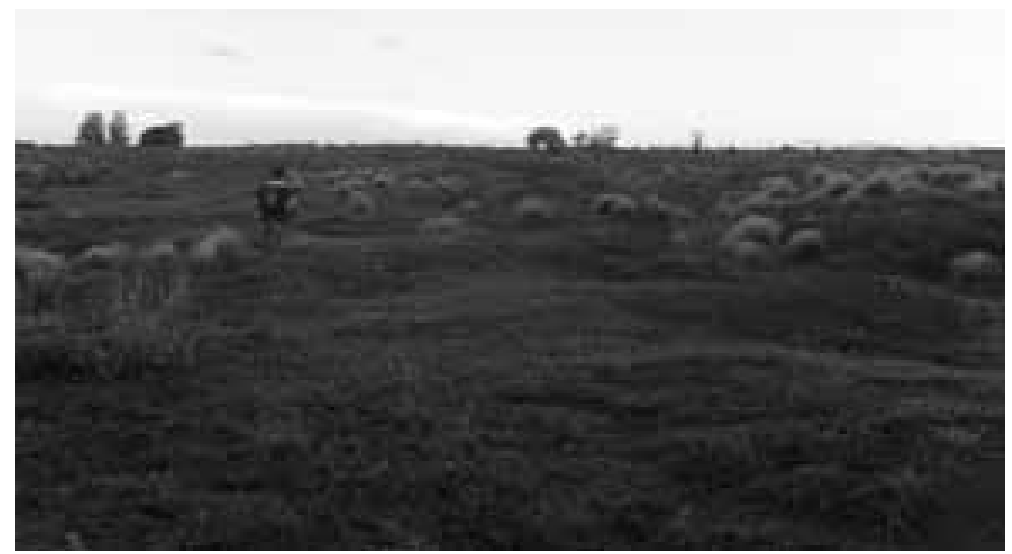




\begin{tabular}{l|l|}
\hline \multicolumn{1}{|c|}{ É POSSÍVEL RECUPERAR } & \multicolumn{1}{c|}{ HÁ NECESSIDADE DE REFORMA } \\
\hline $\begin{array}{l}\text { Áreas com ausência de plantas da espécie } \\
\text { forrageira de interesse menores do que } 2 \mathrm{~m} 2\end{array}$ & $\begin{array}{l}\text { Áreas com solo exposto ou coberto por plantas } \\
\text { daninhas maiores do que } 2 \mathrm{~m} 2\end{array}$ \\
\hline $\begin{array}{l}\text { Existe pelo menos uma touceira/m2 de } \\
\text { capim-solonião ou capim-elefante }\end{array}$ & $\begin{array}{l}\text { Em vários locais da pastagem, encontra-se área } \\
\text { de } 1 \mathrm{~m} 2 \text { com ausência de plantas da espécie de } \\
\text { interesse }\end{array}$ \\
\hline $\begin{array}{l}\text { Existem pelo menos duas touceiras/m2 das } \\
\text { variedades de capim-braquiária }\end{array}$ & $\begin{array}{l}\text { Quando há necessidade de se trocar a espécie } \\
\text { forrageira, por motivos como a implantação de } \\
\text { uma espécie forrageira resistente a cigarrinhas } \\
\text { ou o uso de uma pastagem com maior potencial } \\
\text { produtivo }\end{array}$ \\
\hline
\end{tabular}

Figura 2: Critérios para tomada de decisão quanto à reforma ou a recuperação de uma pastagem degradada Fonte: Oliveira e Corsi (2005).

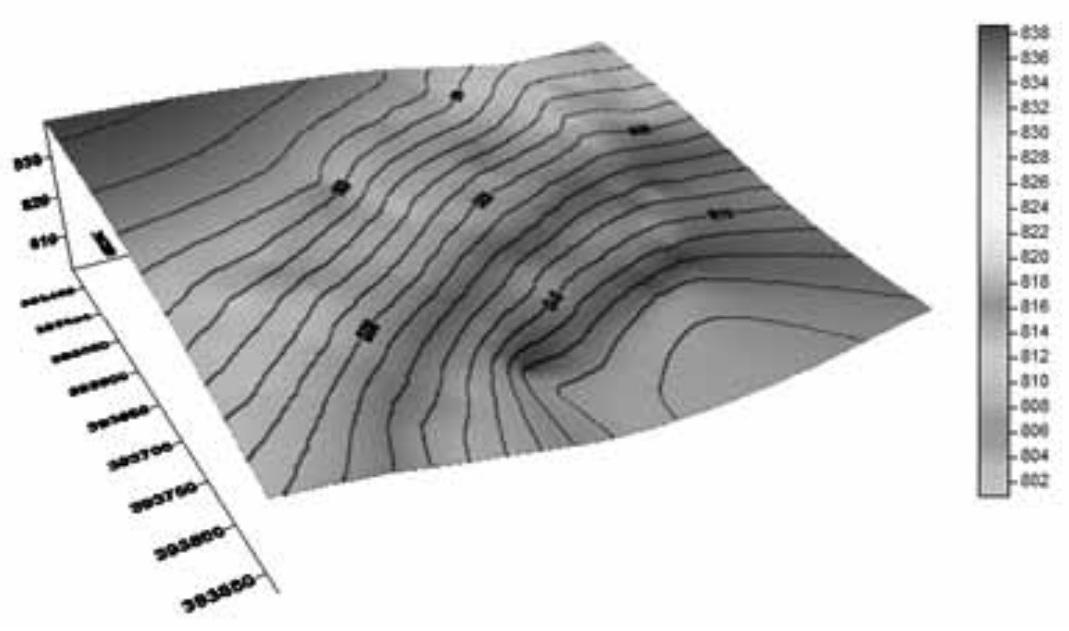

Figura 1: Perfil planialtimétrico tridimensional da propriedade. Fonte: Nogueira, Brito e Oliveira (2012). Software SurferTM

\section{3 | Resultados e discussão}

Seguindo a metodologia de análise de Stoddart, Smith e Box (1975), foram observados distúrbios fisiológicos da espécie dominante, onde se visualizou sintomas de deficiência mineral na forrageira implantada; mudanças na composição botânica, com tamanhos diversos de touceiras e a composição das touceiras apresentando modificações foliares, de caule e de raiz e invasão por novas espécies, no caso alta quantidade de plantas daninhas.

Nascimento Júnior et al. (1994) propõe que qualquer critério para avaliar o estágio de degradação das pastagens tem que, necessariamente, considerar a diminuição da produção e as mudanças na composição botânica, e em última análise a estabilidade do solo (grau de erosão).

Utilizando-se da metodologia trabalhada por Oliveira e Corsi (2005), observou-se que áreas maiores que $2 \mathrm{~m}^{2}$ não apresentavam a $B$. decumbens e estavam tomadas por plantas daninhas ao longo de vários locais na pastagem, tomando-se assim a decisão de reformar a pastagem.

De acordo com Oliveira e Corsi (2005), estabelecer ou reformar uma pastagem consiste em eliminar a população de plantas existentes em determinada área, por meio de preparo do solo ou por meio de herbicidas dessecantes, quando se visa implantar nova espécie forrageira, quer via plantio direto, semeadura convencional ou mesmo plantio por mudas. Os autores sugerem algumas técnicas indicadas para a recuperação das pastagens degradadas, como a utilização do sistema Voisin de pastejo, o plantio de leguminosas nas áreas degradadas, a utilização de grade pesada, a ressemeadura da planta forrageira associada com plantio de uma cultura anual, a vedação por longos 
períodos de tempo e a integração lavoura-pecuária, entre outras.

Após a identificação do perfil altimétrico e do caminhamento da água no terreno, pode-se tomar providência quanto ao manejo do escoamento da água para o controle do processo de erosão. Como o solo da propriedade em questão está muito compactado, quando ocorre precipitação observa-se escoamento da água em superfície, promovendo um processo de erosão laminar. Pelo fato do solo encontrar-se demasiadamente exposto à ação do ambiente, a precipitação promove a desestruturação das partículas em superfície tornando-as propícias a serem carreadas pelo escoamento da água.

Foram observados dois processos erosivos instalados: a erosão laminar e o início de uma voçoroca. Para contenção do processo de erosão laminar devem-se promover barreiras físicas para que se interrompa o escoamento da água em superfície, tais como a construção de terraços e de bacias de contenção para o acúmulo desta água.

Na presente área serão empregadas técnicas vegetativas para o controle da voçoroca. As técnicas de caráter vegetativo são de mais fácil aplicação, menos dispendiosas e mantêm o terreno cultivado em condições próximas ao seu estado natural, devendo, portanto ser privilegiadas (CUNHA; GUERRA, 1999).

O controle da voçoroca consistirá na sua estabilização, tanto em largura como em profundidade. A primeira medida a ser adotada é o desvio do fluxo de água e/ou medidas de controle da velocidade e do volume da água. Há a necessidade da quebra da energia hidráulica da água para não haver mais escoamentos.

Para a reforma da pastagem será necessário o preparo do solo, diante do seu alto grau de compactação. O solo deverá ser revolvido para a instalação de nova forrageira, posteriormente a subsolagem para promover a descompactação deste solo e gradagem de nivelamento. Construções de terraços em nível atuarão como barreira física ao escoamento da água, permitindo o seu acúmulo na base do terraço (e com solo descompactado) e a infiltração da água no solo.

Nascimento Júnior (2001) aponta três medidas importantes na recuperação de pastagens no início de degradação: (a) manejo da pastagem; (b) controle de invasoras; e (c) melhoramento da fertilidade do solo.
O manejo da pastagem começa com o ajuste da carga animal e as forrageiras que, estando sob menor pressão de pastejo, terão maiores chances de rebrotação e produção de sementes. Esta medida também inclui a vedação da pastagem em épocas estratégicas ou nos períodos que coincidem com a germinação das sementes e o desenvolvimento de novas plântulas.

As plantas invasoras das pastagens são as que apresentam considerável capacidade de sobrevivência (elevada produção e disseminação de sementes) e baixa palatabilidade aos animais. O controle de invasoras, visando à recuperação da pastagem, normalmente inclui práticas como a aração, o roço, o arranquio ou o uso de herbicidas.

A manutenção da fertilidade do solo é fundamental para a persistência das pastagens e a consequente garantia de produção animal. Alguns solos, originalmente férteis, perdem sua fertilidade, principalmente por efeito da erosão, ou esgotamento por superpastejo. Para restaurar a fertilidade do solo, todos esses fatores devem ser corrigidos, mas geralmente é também necessário compensar as deficiências nutricionais, aplicando fertilizantes.

\section{4 | Conclusão}

A área de pastagem estudada encontra-se em um alto grau de degradação, sendo necessária uma rápida intervenção para controle dos processos erosivos (laminar e a voçoroca). Além do controle físico do processo erosivo, outras técnicas deverão ser aplicadas para conter o processo de degradação da pastagem, tais como, o controle de plantas daninhas, o manejo da pastagem e a reconstrução da fertilidade do solo.

\section{Agradecimentos}

Agradecemos ao IFSULDEMINAS pelo apoio técnico e financeiro para o desenvolvimento e a conclusão deste trabalho. 


\section{Referências bibliográficas}

ALVARENGA, M.I.N. e DAVIDE, A.C. Características físicas e químicas de um latossolo vermelho-escuro e a sustentabilidade de agrossistemas. Revista Brasileira de Ciência do Solo, v.23, p.933-942, 1999.

BARBOSA, M.A.A.F. Ecologia em relação ao pastejo. 2001. Disponível em: <www.tdnet. com.br/domicio/Ecolog.htm>.

Acesso em: 18/11/2012.

CORDEIRO, F.C. et al. Diversidade da macrofauna invertebrada do solo como indicadora da qualidade do solo em sistema de manejo orgânico de produção. Revista Universidade Rural: Série Ciências da Vida, Seropédica, v.24, n.2, p.29-34, jul./dez. 2004.

CUNHA, S.B.; GUERRA, A.J.T. Erosão e Conservação dos Solos: conceitos, temas e aplicações. 3 ed. Rio de Janeiro: Bertrand Brasil, 1999.

GOMES, G.L.M. Diagnóstico de áreas degradadas por voçorocas no município de Alterosa/MG. Dissertação (Mestrado). 2006. 59 p. Universidade de Ribeirão Preto, Ribeirão Preto.

NASCIMENTO JÚNIOR, D. Recuperação de pastagens degradadas: conceito de sustentabilidade. 2001. Disponível: <www. tdnet.com.br/do.../RECUPERACAO_DE_ PASTAGENS_DEGRADADAS.ht>.

Acesso em: 18 nov. 2012.

NASCIMENTO JÚNIOR, D.; QUEIROZ, D.S.; SANTOS, M.V.F. Degradação das pastagens e critérios para avaliação. In: Peixoto, A.M.; Moura, J.C.; Faria, V.P. (eds.). SIMPÓSIO SOBRE MANEJO DE PASTAGEM, 11, Piracicaba, 1994. Anais... Piracicaba: FEALQ, 1994. 325P.

OLIVEIRA JÚNIOR, R.C.; MEDINA, B.F. A erosividade das chuvas em Manaus (AM).

Revista Brasileira de Ciência do Solo, Viçosa, v.14, n.2, p.235-239, 1990.
OLIVEIRA, P.P.A.; CORSI, M. Circular Técnica 38: recuperação de pastagens degradadas para sistemas intensivos de produção de bovinos. São Carlos: Embrapa, 2005. 23p.

SILVA, A.C.; LIMA, J.M.; CURI, N. Relação entre voçorocas usos da terra, solos e materiais de origem na região de Lavras (MG). Revista Brasileira de Ciência do Solo, Campinas, p.459-464, 1993.

SILVA, R.C.S.; ALMEIDA, J.C.R.; BATISTA, G.T.; FORTES NETO, P. Os indicadores físicos, químicos e biológicos da qualidade do solo e da sustentabilidade dos ambientes naturais. Repositório Eletrônico Ciências Agrárias, 2011. p. 1-13. Disponível em: <www.agro. unitau.br/dspace>.

Acesso em 18 nov. 2012. Coleção Ciências Ambientais.

STODDART, L.A.; SMITH, A.D.; BOX, T.W. Range management. New York: Mcgraw-Hill Book, 1975, $431 \mathrm{p}$. 